\title{
Picky City Bats: Variation in Urban Conditions Generates a Suitability Gradient that Structures the Bat Community.
}

\section{Mauricio Rodríguez-Ramírez}

Universidad Michoacana de San Nicolás de Hidalgo

\section{Miguel Angel Salinas-Melgoza}

Centro de Investigaciones en Geografía Ambiental-UNAM

\section{Vicente Salinas-Melgoza}

Instituto Tecnológico del Valle de Morelia

\section{Yvonne Herrerías-Diego}

Universidad Michoacana de San Nicolás de Hidalgo

Alejandro Salinas-Melgoza ( $\sim$ alejandro.salinas@umich.mx )

Universidad Michoacana de San Nicolás de Hidalgo https://orcid.org/0000-0003-2024-3061

\section{Research Article}

Keywords: Chiroptera, Ecology, Habitat suitability, Diversity, Urban gradient

Posted Date: June 28th, 2021

DOl: https://doi.org/10.21203/rs.3.rs-647832/v1

License: (a) (i) This work is licensed under a Creative Commons Attribution 4.0 International License. Read Full License 


\section{Abstract}

The transformation of natural systems into urban cities represents a radical habitat modification and one that generates species-specific effects on bat communities. Cities present heterogeneous mosaics of urban conditions, which the bats can inhabit differentially by utilizing their intrinsic characteristics. We expected bat species richness, number of abundant species and feeding guilds to be positively impacted by an increased degree of suitability for bats in certain areas interspersed in the city. We also expected that the number of dominant species would follow an inverse pattern, with some species being fostered in less suitable areas for bats. We determined the levels of suitability for the presence of bats in urban-based basic geostatistical units (BGUs) in the Neotropical city of Morelia, in Michoacán state, Mexico. We identified three levels of suitability for bats, low, medium and high, using the percentage of arboreal vegetation and constructed and open areas in the BGUs. We monitored the bat assemblage monthly over an annual cycle using autonomous ultrasonic recorders to assess the abundance of each species at each suitability level. Across all three suitability levels throughout the year, we found a high dominance of three insectivorous bat species that forage in open areas. Diversity measures supported our predictions, agreeing with bat flight and foraging functional traits. These results highlight the importance of city features in driving bat diversity and how urban planning that fails to consider key city features, such as arboreal areas in the city, may reduce suitability for bats, leading changes in diversity.

\section{Introduction}

The transformation of natural habitats into cities constitutes one of the most radical changes to nature. These changes are so dramatic that the usual result is the generation of conditions with negative effects on biodiversity (Turner et al. 1994; Oprea et al. 2009; Fabianek et al. 2011; Lintott et al. 2014; Jung and Threlfall 2018). This type of habitat modification mainly results from loss of the original arboreal vegetation that leads to land use change towards anthropic-associated cover types (López et al. 2001; Ortega-Álvarez and MacGregor-Fors 2009). Species may vary in their degree of susceptibility to habitat modification due to intrinsic characteristics, leading them to respond differentially to the perturbation (Hourigan et al. 2006; Meyer et al. 2008; McCleery 2010; Lintott et al. 2014; Jung and Threlfall 2018). While some species can increase their numbers if habitat modification leads to conditions that foster their presence, other species can opt to leave the modified habitat in search of new sites with lower levels of modification while some other species can also establish in suboptimal modified sites and tolerate these new conditions in urban-modified areas. One of the generalized responses of animal species, as human modification of the habitat increases and the original vegetation gives way to urban areas, is a gradual reduction in biodiversity (Kurta and Teramino 1992; Blackthorn 2013; Arroyo-Rodríguez et al. 2016).

The impact on biodiversity of the transformation of natural habitat into cities has been evaluated along a gradient of urban conditions, as well as per land-use type. While the former includes areas with a systematic set of increasing or decreasing urban conditions (Agosta 2002; Jung and Kalko 2011; Li and Wilkins 2014; Jung and Threlfall 2016), the latter considers areas of the cities from a functional point of view, such as residential or commercial zones (Avila-Flores and Fenton 2005; Suarez-Rubio et al. 2018). 
These studies provide systematic support for changes in local conditions in order to foster the presence and increase the abundance of some species, while others are eliminated or reduced in number.

Some cities present a gradient in urban conditions as a function of the distance between the periurban areas and city center. This assumes a consistent reduction in the degree of modification with increased distance towards the periphery of the city (Ortega-Álvarez and MacGregor-Fors 2009; Moretto and Francis 2017). The generalized response to this distance effect is a reduction in species abundance and richness with increased human impact as one gets closer to the city center (Ortega-Álvarez and MacGregor-Fors 2009; Dixon 2012; Bazelman 2016; Moretto and Francis 2017). These studies also indicate the increased dominance of a few species as human impact increases, particularly for generalist species that can more efficiently exploit urban areas with the greatest modification (Jung and Threlfall 2016). Local features that can influence the presence of bats include the vegetation structure, which interacts with bat functional traits such as wing morphology, vocalizations and foraging strategies (Duchamp and Swihart 2008; Chambers et al. 2016; Ramírez-Mejía et al. 2020). An example of this is provided by the aerial insectivorous bats, which are characterized by presenting reduced wing loadings and constant-low frequency echolocation calls and have been associated with areas of little or no arboreal vegetation typical of the urban matrix in which they thrive.

However, this notion of decreased diversity with distance fails to consider the complexity of cities and the wide range of conditions they present within their matrix. This variability of conditions includes not only forested areas such as urban parks, which fosters high diversity, but also other city features such as buildings, water bodies and rural areas, providing suitable conditions for an even larger array of species. Along a continuum towards the interior of cities, considering the variety of city features present, this distance gradient may therefore not be applicable. Such variability in city features could produce a higher richness and increased abundance in areas of intermediate disturbance, such as the periurban areas, since these can provide a higher variability of habitats to support greater biodiversity (Hourigan et al. 2006; Threlfall et al. 2011; Li and Wilkins 2014). This indicates that there could be gradual subtle changes within cities, with an array of environmental conditions driven by city features that produces areas with speciesspecific suitability of conditions, and suggests there could be areas that differ in terms of their suitability for bats in a graded manner, but are interspersed within the city matrix. This gradient of suitability could provide a variety of areas of different quality for a range of species across the city. Some areas would foster increased richness and abundance for some bat species as a function of their intrinsic characteristics, while some other species would not thrive (Dixon 2012; Bazelman 2016; Jung and Threlfall 2018). This suitability gradient for bats would then be an inherent feature of the city matrix given the nature of its urban features. However, this notion of the occurrence of different suitability levels (Li and Wilkins 2014; Moretto and Francis 2017; Gili et al. 2020), regardless of distance from the city center, but rather interspersed in the city, has seldom been the subject of study.

Seasonality is another factor that influences the species richness and abundance of city fauna. Seasonality can modify the abiotic conditions of a site, particularly in terms of temperature, relative humidity and daylight length (Collado-Ardón et al. 2001; Miguélez et al. 2013; Ramos and Meza 2017). 
These modifications can dictate the availability of food resources for many animal species, as well as their activity patterns (Gonsalves and Law 2018; Salvarina et al. 2018). Hence, the presence and abundance of a given set of bat species in a particular site can be influenced by seasonal changes over the course of the year. One example of this is the presence of the nectarivorous bat species Leptonycteris yerbabuenae, which can be influenced by the seasonal occurrence of flower resources as it migrates south in the tropical areas of Michoacán state, in Mexico (Racey and Entwistle 2000). A positive relationship has also been found between the seasonal abundance of some insectivorous bat species and that of insects in tropical and temperate forests (Montiel et al. 2006; Novaes et al. 2017; Salvarina et al. 2018). Although seasonal change in food resource availability is considered the main driver influencing the abundance of plantivorous and animalivorous bat species in non-urban areas (Cisneros et al. 2015), to our knowledge, there have been few evaluations conducted in cities, and those that have assessed the influence of seasonality in cities have been performed for only a limited number of species at a time, and have not considered the bat assemblages as a whole (Rollinson et al. 2013; Novaes et al. 2017; Gonsalves and Law 2018).

Variation in urban conditions thus creates areas with different features that, in turn, generate different suitability levels for bat presence, which does not necessarily agree with the approach of distance from the center of the city. In this study, we aimed to evaluate the effect on the bat assemblage of a suitability gradient interspersed within the urban matrix of Morelia city, Mexico. We also aimed to evaluate the impact of seasonality on this bat assemblage along a suitability gradient. We hypothesized that intrinsic bat characteristics, such as flight and foraging functional traits, would enable differential use of the urban habitat and thus foster the presence of certain species in some areas, while excluding other species from less suitable areas. We have four predictions in two sets that highlight the overall agreement of the suitability level with the expected dimensions of diversity driven by the species-specific differential effects of human impact on the city suitability levels for bats. The first set of predictions considers the negative impact of urbanization on some bat species as a result of a reduction in the degree of suitability for bats, in which: a) the bats will present reduced species richness and number of relative abundant species, and b) feeding guilds such as frugivorous bats will be either reduced in species number or lost. The second set of predictions invokes the positive effects of habitat modification on some species, in which: c) there will be an increase in the number of dominant bat species, $d$ ) the aerial insectivorous guild will be widely distributed in the city given the openness of the urban matrix due to the presence of constructed and open areas. Furthermore, given the influence of food resources on changes in bat abundance (Gomes et al. 2013; Cisneros et al. 2015), we also expect that abundance values will increase during the rainy season, particularly for the insectivorous bat species.

\section{Methods}

\section{Study site}

The study was conducted in the city of Morelia, in Michoacán state, Mexico $\left(19^{\circ} 52^{\prime}\right.$ to $19^{\circ} 26^{\prime} \mathrm{N}$ and $101^{\circ} 02^{\prime}$ to $101^{\circ} 31^{\prime} \mathrm{W}$ ). Morelia covers an area of $67.2 \mathrm{~km}^{2}$ (IMPLAN 2018) and presents a minimum temperature of 
$10.4^{\circ} \mathrm{C}$ and maximum temperature of $27.5^{\circ} \mathrm{C}$ throughout the year, with an average annual rainfall of 796.5 $\mathrm{mm}$ (Servicio Meteorológico Nacional 2019). A total of $75 \%$ of the annual rainfall occurs from June to September, followed by a dry season that extends from October to May. Morelia is a medium-sized city with a population of 743,275 inhabitants in 2020 (INEGI 2021), and $400 \%$ growth towards the periphery recorded in the last three decades (López et al. 2001). Most of our understanding of the response of fauna in cities is derived from large urbanized areas such as Mexico City (Avila-Flores and Fenton 2005) and Sydney (Threlfall et al. 2011, 2012a); however, the most common urban settings in which animals are found are medium-sized cities (Jung and Kalko 2010; Li and Wilkins 2014; Moretto and Francis 2017; Rodríguez-Aguilar et al. 2017). Previous studies in Morelia indicate the negative effects on the bat community of proximity to the city. This negative impact caused a loss of feeding guilds towards the interior of the city, mainly the nectarivorous species (Martínez-Mijares 2016), while feeding guilds such as the frugivorous and insectivorous bats were favored in areas with arboreal vegetation (Martínez-Mijares 2016).

\section{Selection of sampling units and estimation of suitability level gradient for bats in Morelia}

For sampling, we used the units defined by the Mexican Instituto Nacional de Estadística y Geografía (INEGI) that are used periodically for national human population censuses in Mexico (INEGI 1980, 2010). These sampling units are known as Basic Geostatistical Units, or BGUs (also known as AGEBs, by their Spanish acronym) and are fixed polygons, delimited by streets around a set of blocks, among which comparisons can then be made (INEGI 1980, 2010). The use of these BGUs may enable us to delimit areas within the city that can be characterized by a set of parameters representing different levels of given urban characteristics. All BGUs in the city can then be associated along a gradient of suitability for bats, drawn from a set of parameters. Only urban BGUs within the limits of the city of Morelia were included in our sampling.

To obtain a representation of the gradient of suitability for bats in Morelia city, we produced a land use cover map for the city. We used 2018 Landsat 8 satellite images to create this map. We classified the entire city into three cover types: a) areas with arboreal vegetation, b) open areas, presenting neither arboreal vegetation nor human constructions such as buildings and houses, and c) constructed areas that included houses and buildings. The map was obtained from training fields for all three cover types distributed throughout the city, using the Raster package (Hijmans 2019) for R 3.5.0 (R Core Team 2020). These training fields provided information at pixel level from satellite images. A supervised classification was subsequently performed using a classification and regression tree with the rpart package for $\mathrm{R}$. The percentage of each cover type per BGU was obtained. The set of variables used to construct this map has been previously associated with the presence of bats (Li and Wilkins 2014).

The land use cover map was then used in a multicriteria analysis using ILWIS 3.3 to obtain the suitability gradient map for Morelia city. For this multicriteria analysis, we used the percentage of each cover type per BGU obtained from satellite images in raster format. All three variables were standardized to between 0100 , in which 100 represented the optimal suitability level for bats. Standardized variables were then 
weighted, based on expert opinion, in order to indicate how they could influence the presence of bats as a whole, rather than on a species-by-species basis. Arboreal vegetation had the highest weighting value in the analysis (0.50). This analysis assigned BGUs in Morelia to one of three categories along a suitability gradient for bats. Low suitability level BGUs were represented to a greater extent to the north of the city, while the BGUs assigned to the medium suitability level were located mostly to the south of the city. High suitability level BGUs were located in the periphery and to the south of the city (Fig. 1). We selected four BGUs per suitability level, and acoustic monitoring was performed in each. Given that the selection of BGUs per suitability level was constrained to their location within the city (i.e. low suitability levels were mostly located to the north and medium and high suitability levels to the south of the city), as well as to the context in which they were located (i.e. we aimed to select BGUs that were surrounded by BGUs of a similar level category), their distribution per level was not homogenous across the city. The high suitability level category recorded the largest BGU average area $\left(0.61 \pm 0.22 \mathrm{~km} 2\right.$, range $\left.=0.38-0.81 \mathrm{~km}^{2}\right)$, compared to the low $\left(0.45 \pm 0.23\right.$, range $\left.=0.17-0.68 \mathrm{~km}^{2}\right)$ or medium $\left(0.54 \pm 0.18 ; 0.42-0.81 \mathrm{~km}^{2}\right)$ suitability levels. We also obtained the percentage of land use cover type per suitability level. The BGUs that were classified as low suitability presented, on average, more open (average $=56 \%$, range $48 \%-64 \%$ ) and constructed (average $=42 \%$, range $32 \%-52 \%$ ) areas, and a lower percentage of arboreal vegetation (average $=2 \%$, range $0 \%-5 \%$ ), while those of high suitability recorded the highest percentage of arboreal vegetation (average $=52 \%$, range $42 \%-63 \%$ ) and a lower percentage of constructed areas (average $=15 \%$, range $10 \%$ - 19\%) (Table 1).

\section{Experimental design for acoustic monitoring of bats}

We monitored the bat assemblage at each of the four selected BGUs per suitability level in the city through passive acoustic monitoring, performed from November 2018 to October 2019 for four days each month, two days before and two days after the new moon in order to avoid the incidence of lunar phobia. Three BGUs were sampled simultaneously each day, one BGU per suitability level each night per month. Inclusion of each BGU in a given sampling day was random each month. Sampling sessions were conducted from 30 minutes before sunset and lasted for up to eight hours (Hourigan et al. 2006). No sampling was conducted on days with rain and wind. Sampling was performed using Song Meter SM4BAT FS autonomous ultrasound detectors in conjunction with an omnidirectional SMM-U1 ultrasonic microphone (Wildlife Acoustics 2016). The sites where these bat detectors were placed included the rooftops of houses and buildings, surrounded by more houses, which are the most common type of construction in the city, as well as buildings that are characteristic of the city. These sites were selected based on logistic accessibility, while also ensuring that the equipment would not be stolen. Microphones were placed in a site on average $4.99 \pm 14.4$ (range $4.95-5.45$ meters, $n=12$ ) $m$ above ground level at a $45^{\circ}$ angle facing open areas with no obstacles. Monitoring was performed with the ultrasonic recorders configured such that an acoustic event was recorded when all of the following conditions were met: the sound reached at least $12 \mathrm{~dB}$ and had a duration of at least $1.5 \mathrm{~ms}$. In addition, a bat pass event was recorded in independent files during surveys when the time elapsed between separate acoustic events was at least $3 \mathrm{~s}$. The microphone was set at $12 \mathrm{~dB}$ gain with no high-pass filter. Recordings were obtained in wav format at a sampling rate of $500 \mathrm{kHz}$. 


\section{Data sets for analyses}

We used data from two sources: 1) a reference dataset with data of acoustic features of bat calls identified at species-level from a previous study (Zamora-Gutierrez et al. 2016) for training a Random Forest model, and 2) a field dataset with acoustic parameters obtained from recordings from a monitoring survey of bats.

\section{Data for training Random Forest model}

We obtained a data set to train a Random Forest model. Random Forest (RF) is a tree-based modeling procedure for classification and regression problems to overcome the disadvantages of using a single Classification and Regression Tree (CART), including improvement of stability and reduction of overfitting (Breiman 2001). RF produces a set of several independent trees using a random subset of sample data points along with independent variables at each split, and utilizes ensemble techniques to combine the output of the trees in order to improve predictive performance (Breiman 2001). RF has been previously used to successfully identify bat species using acoustic parameters from ultrasound bat recordings (Zamora-Gutierrez et al. 2016; López-Baucells et al. 2019). We first obtained a list of the bat species potentially present in the study area by consulting four sources: Núñez-Garduño (2005), Medellín et al. (2007), Ceballos and Arroyo-Cabrales (2012) and CONABIO (2018), which yielded 43 species (Supplementary material, Table 1). We then obtained a subset of records from the reference dataset (Zamora-Gutierrez et al. 2016) with the acoustic parameters for the list of bat species potentially present in the study area. The reference dataset included 27 acoustic parameters for search phase recordings/calls for 59 bat species occurring throughout Mexico, and is freely available from Dryad (https://datadryad.org/stash/dataset/doi:10.5061/dryad.760r8). However, only species with potential distribution in our study site were used.

\section{Acoustic data from monitoring of bats for species identity assignation}

We obtained a number of acoustic parameters from field recordings to be used in the assignation of species identity. We automatically obtained seven acoustic parameters in recordings obtained from monitoring using the software Kaleidoscope Pro 3: i) constant frequency ( $F c$ ), ii) maximum frequency (Fmax), iii) minimum frequency (Fmin), iv) bandwith (Bndwdth), v) knee frequency (Fk), vi) duration (Dur), vii) initial slope (S1). Evaluation of the acoustic information provided by these parameters (Wildlife Acoustics 2016) indicated that they were equivalent to those used by the reference dataset. Additional acoustic variables obtained from recordings using Kaleidoscope included: average characteristic slope (Sc); average mean frequency (Fmean); average time between calls (TBC); average time to the knee (Tk); average time to the characteristic. However, these were not used in the species identity assignation since it was not possible to assign an equivalent to those used in the reference dataset. The variable of recording quality (Qual) was also obtained, but was used only during the depuration process and was excluded from the other analyses. Our database obtained from field surveys was subject to a process of data depuration as described below. 


\section{Random Forest model training and species identity assignation}

We used the Random Forest (RF) analysis in the caret package (Classification and Regression Training) (Kuhn 2008) for R 3.5.0 (R Core Team 2020) to assign species identity to each bat pass event recorded in the bat acoustic monitoring. This assignation of species identity comprised two steps. In the first step, we conducted a RF in which we first used the subset of acoustic parameters from the reference dataset for previously identified bat species that potentially occur in the study area. We then split this subset into a training sub-dataset, which contained $80 \%$ records from the subset of the reference dataset, and a validation sub-dataset with the $20 \%$ remaining records. We trained the model using the training subdataset. The trained RF model was constructed with 1,000 trees. For model training, we used model parameters similar to those of the reference source. Three predictor variables were randomly sampled at each stage. The resampling method used was 5 -fold cross-validation, using the five groups previously defined by the original authors from the reference dataset. We used the automatic grid search, with 1974 as the seed set. The variable to predict with the RF was bat species identity, using the 7 acoustic parameters as predictors. Finally, we validated predictions with the validation sub-dataset from the reference dataset. The predictive performance of the model for species identification was evaluated using accuracy. The resulting predictive performance of the trained model for species identification had an overall average accuracy of $65 \%$ in terms of correct classification. The worst performance in the training dataset occurred with Molossus sinaloae and the Corynorhinus phonotype (Supplementary material

Table 3). In the second step, we predicted species identity for each recorded bat pass, from field data using the previously trained RF model (Supplementary material, Fig. 2).

\section{Process of data depuration}

We performed a process of depuration on the files where a species was assigned in order to obtain recordings that were more suitable for analysis. We initially considered 38,625 bat pass events recorded in independent files during surveys. Prior to performing the analyses for species identity assignation, we first excluded 16,240 files with less than or equal to three echolocation pulses from those bat passes recorded during surveys (Hourigan et al. 2010). We then used the variable Qual, obtained from Kaleidoscope (see above), as a proxy for the quality of recordings. We excluded 5,394 additional recordings for which the quality values were in the first quartile, in order to ensure we were using the highest quality records in subsequent analyses. As a proxy for precision of species identification, we then obtained accuracy values for each species using the package RandomForest. Only species with accuracy values $\geq 0.4$ were included in the analyses. Accuracy values ranged from $0-1.0$, and 6,065 records with accuracy value $<0.4$ were therefore assigned to an unknown species category and excluded from further analysis. We then obtained the relative abundance of each bat species by measuring its occurrence at one-minute intervals, rather than the number of times it was recorded during this one-minute period. The total number of one-minute intervals at which the species occurred for the complete sampling night per BGU was used as a proxy for the relative abundance of each species (Miller 2001). This procedure has been used to obtain abundance estimations in other animal groups, such as birds (Celis-Murillo et al. 2009, 2014), and has been correlated 
with visual estimations of abundance in bats (Gehrt and Chelsvig 2003). This procedure enabled us to not only reduce bias due to incorrect species assignation, but also to reduce overestimations (Miller 2001; Hourigan et al. 2010; Trejo-Ortiz 2011). Thus, we obtained a dataset of 10,188 records of the occurrence of bat species during the one-minute intervals.

Once a species identity was assigned to each bat pass, the acoustic records of the species were reviewed manually 90 min after initiating each recording session and again at $90 \mathrm{~min}$ after the end of each recording session. This was conducted in order to exclude urban sounds or those of non-bat species that are common in the urban soundscape during the sampling schedule. We then excluded 2,436 records from further analysis because these were not recordings of bat species. In addition, notable records, such as those for species with few records or belonging to the same genus, were also revised manually to ensure that the species were correctly assigned. These species included Eptesicus furinalis Artibeus-Sturnira phonotype, Molossus molossus, $M$. rufus and $M$. sinaloae. There are a number of species that have presented low performance in previous classification works (Pio et al. 2010; Zamora-Gutierrez et al. 2016), and some of these species identified in the species assignation procedure were therefore assigned to phonotypes. Records assigned to different species from the genus Artibeus and Sturnira were grouped into an Artibeus-Sturnira phonotype. Records assigned to Corynorhinus mexicanus and $C$. townsendii were indicated as a Corynorhinus phonotype. All records assigned to the different Myotis species potentially occurring in the study area were grouped into a Myotis phonotype. Finally, we excluded five species that contained $<10$ records from further analyses (Kloepper et al. 2016), although these species are considered in the taxonomic list. These excluded species comprised 18 records, which corresponded to Lasiurus blossevillii, Leptonycteris yerbabuenae, Molossus sinaloae and to the Corynorhinus and Myotis phonotypes. This process of quality verification yielded a final database that comprised 7,726 records.

\section{Data analysis}

Data analysis was performed per BGU at two levels: 1) the complete annual sampling period, and 2) the dry and rainy seasons separately. The dry season comprised the period October to May, while the rainy season comprised June to September. We created rank relative abundance plots per suitability level. Estimations of diversity per BGU were obtained by calculating the first three Hill numbers (Hill 1973; Jost 2006; Moreno et al. 2011) using the iNEXT package for R (Hsieh et al. 2016) as a way to obtain comparable dominance and equitability values. The first Hill number (q0) indicates species richness, the second Hill number (q1) is a measure of the effective number of species with similar abundance values, and is derived from the exponential value of the Shannon index, and the third Hill number (q2) evaluates the effective number of dominant species, and is the inverse of the Simpson index. These Hill numbers are expected to represent the number of effective species in each sample for each component of diversity (Hill 1973; Moreno 2001; Moreno et al. 2017).

To evaluate the similarity in bat species composition among BGUs with different levels of suitability, we performed non-metric multidimensional scaling (NMDS). We used a Bray-Curtis similarity matrix, considering bat species richness and relative abundance. We used the stress value as a measure of the goodness of fit in the data ordination, with a range of 0 to 1 . Stress values closer to 0 indicate better 
ordination relative to the original data (Oksane et al. 2019). The NMDS graph represents the degrees of similarity among points in terms of bat richness and relative abundance. The points representing BGUs located further apart in the NMDS ordination space present greater differences than those of BGUs in greater proximity to each other. We plotted the first two NMDS axes, and overlaid fitted contours of the percentage of arboreal cover, constructed cover and open area cover per BGU onto the ordination space. Fitted contours were obtained using the ordisurf function of the vegan package for $R$, and the values plotted in the ordination space indicated the degree of association between these BGUs and the variable.

Finally, to evaluate whether suitability level and season could help to explain variance in the diversity components of q0, q1, and q2, and relative abundance per bat species, we constructed generalized linear mixed models (GLMMs) independently. In all models, suitability (with three levels) and season (with two levels) were considered as fixed effects. Since we were interested in the influence of coarse-grain city features such as areas of suitability for bats, we concentrated our analysis on this level. The BGU and suitability level were considered as random factors in each model to account for the lack of independence. This enables us to take into account the systematic non-explained variation (Faraway 2016), due to the use of several sampling units per suitability level. For the q0 model, we used a negative binomial error distribution with the Ime4 package (Bates et al. 2015). Both q1 and q2 models were performed using lognormal error distributions with the Ime4 package. For the relative abundance model, we used a zeroinflated with negative binomial error distribution using the glmmTMB package (Brook et al. 2017). We used a significance level of $p<0.05$, and all analyses were performed in $R$.

\section{Results}

\section{Bat richness and abundance in Morelia}

We sampled for 48 nights in 12 BGUs in Morelia, for a total of 7,726 recording minutes. We recorded 14 species, belonging to 15 genera, five families, and three phonotypes. We also recorded three feeding guilds, considering the classifications proposed by Kalko et al. (1996): 1) aerial insectivorous bats; 2) gleaning insectivorous bats; and 3) frugivorous bats (Supplementary material, Table 2). The bat assemblage in Morelia was highly represented by insectivorous bat species, which accounted for almost $98 \%$ of the records.

\section{Bat diversity evaluation per suitability level}

Three aerial insectivorous bat species were found to be the most abundant at all three suitability levels: Promops centralis was the most abundant (low suitability: $71 \%$ of all records per suitability level, medium suitability: $71 \%$ of all records per suitability level, and high suitability: $61 \%$ of all records per suitability level), followed by Eumops underwoodi (low suitability: $21 \%$ of all records per suitability level, medium suitability: $13 \%$ of all records per suitability level, and high suitability: $19 \%$ of all records per suitability level) and finally Molossus rufus (low suitability: $4 \%$ of all records per suitability level, medium suitability: $8 \%$ of all records per suitability level, and high suitability: $6 \%$ of all records per suitability level). The bat community per feeding guild and suitability level recorded specific changes. The BGUs of low suitability 
level were characterized by presenting exclusively insectivorous bat species, while those of both medium and high suitability level presented frugivorous bat species, albeit in low numbers. Insectivorous gleaning species showed a positive increase in relative abundance with suitability level. The BGUs of high suitability level also presented an increase in the relative abundance of frugivorous bat species (Fig. 2a). Both specific richness (q0) and the number of species with a similar abundance pattern (q1) increased concomitantly with increased suitability level (Fig. 3a, 3b). Average q0 and q1 values per BGU were lower at the low suitability level (average low: $q 0=7.25$ species, range $=5-10 ; q 1=2.22$ species, range $=1.70-$ 2.94) when compared to the high suitability level BGUs, which presented the highest average number of species (average high: q0 $=9.75$ species, range $7-11 ; q 1=3.30$ species, range $=2.49-4.57$, Fig. 3 a and $3 b)$. However, q2 showed an inverse pattern, with a reduction in the number of dominant species with increased suitability level for bats. The largest average q2 value per BGU was recorded at the low suitability level ( $q 2=2.86$ species, range $=1.91-4.84$, Fig. $3 c$ ), compared to the high ( $q 2=1.83$ species, range $=1.45-2.38)$ suitability level (Fig. $3 c$ ).

\section{Bat diversity evaluation per season}

Overall, all three suitability levels, in both the dry and rainy seasons, were dominated by the three aerial insectivorous bats ( $P$. centralis, E. underwoodi and M. rufus). However, the relative abundance of $P$. centralis was higher in the dry season than in the rainy season. The bat assemblage showed seasonal changes in guild level per suitability level. The low suitability level presented only insectivorous bat species in both seasons, while a higher number of gleaning bat species was recorded during the dry season, compared to the rainy season (Fig. 2b). Although both the medium and high suitability levels presented frugivorous bat species during both seasons, the high suitability level BGUs presented a larger relative abundance of frugivorous bat species during the rainy season (Fig. 2c, 2d). Moreover, a set of insectivorous bats, such as Mormoops megalophylla and M. molossus, presented increased relative abundance during the rainy season in the high suitability level BGUs (Fig. 2d). The average species richness (q0) and the average number of dominant species (q2) were both lower in the rainy season compared to the dry season (Fig. 3d, 3f). In contrast, the number of species with similar abundance pattern values (q1) showed an inverse pattern, with higher average values presented in the rainy season (Fig. 3e).

Results from the GLMMs indicated that the suitability level and seasonality explained the variation in our data, but in different ways. This analysis indicated that the low suitability levels and the high suitability level in the rainy season significantly explained variation for q0, q1, and q2 as a measure of bat diversity in Morelia for the annual sampling period. These results also indicated that variance in the diversity components of q0, q1, and q2 could be explained by the dry season. The largest effect was caused by the dry season for specific richness (q0). The largest effect for the number of species with a similar abundance pattern (q1) was due to a high suitability level in the rainy season, and both dry season and low suitability level equally have the lowest effect. The dry season had the greatest effect in q2, while relative abundance was explained positively solely by the high suitability level in the rainy season (Table 2). Marginal $\mathrm{R}^{2}$ was low in all models.

\section{Similarity in bat biodiversity across the city}

Page $11 / 26$ 
Results from the non-metric multidimensional scaling indicate that species composition and relative abundance varied among suitability levels. For the annual evaluation, the BGUs were segregated in the ordination space according to suitability level. Medium and high suitability level BGUs were more similar in composition and relative abundance in comparison to those from the low suitability level (Stress $=0.093$, Fig. 4a, 4b, and 4c). This pattern, in which high and medium suitability level BGUs overlapped and segregated from the low suitability level, was repeated in the rainy season (Stress $=0.092$, Supplementary material Fig. 1a, 1c, and 1e). However, during the dry season, the NMDS indicated that the BGUs per suitability level were more similar in species composition and relative abundance among each other, since all three suitability levels overlapped (Stress $=0.128$, Supplementary material Fig. $1 \mathrm{~b}, 1 \mathrm{~d}$, and $1 \mathrm{f}$ ). The BGUs distributed in the ordination space according to suitability level also agreed with the overlaid fitted contours of the percentage of open area and constructed area cover types per BGU onto the ordination space for the complete sampling period (open areas: Fig. 4a; constructed areas: Fig. 4b), and for the rainy (Supplementary material, open areas: Fig. 1a; constructed areas: Fig. 1c) and dry (Supplementary material, open areas: Fig. 1b; constructed areas: Fig. 1d) seasons. Conversely, this relationship between suitability level and percentage of cover type was positively related to the percentage of arboreal cover for the complete sampling period (Supplementary material Fig. 4c), as well as for the rainy (Supplementary material Fig. 1e) and dry (Supplementary material Fig. 1f) seasons.

\section{Discussion}

We recorded a species richness of 14 bat species over the one-year sampling period in Morelia; two of those bat species had not been reported in the city in previous studies (Martínez-Mijares 2016; FerreyraGarcía et al. 2017). The greater proportion of bat species recorded in these previous studies were frugivorous bat species captured using ground-level mist nets in forested areas interspersed in the city, in comparison to our study where the largest proportion of the species richness corresponded to insectivorous bat species. This reflects the differences in sampling methods used. The use of mist nets tends to record just a fraction of the bat assemblage (Granados-Herrera 2001; Trejo-Ortiz 2011; Blackthorn 2013), since the capture efficiency of insectivorous bat species overflying the range of the mist nets is reduced (Granados-Herrera 2001; Miller 2001; Mora et al. 2002; Hourigan et al. 2006; Jung and Kalko 2010; Trejo-Ortiz 2011; Blackthorn 2013). These insectivorous bat species comprise precisely the group of bat species that increased using the autonomous recorders. Although we consider that the use of this sampling method reduces underestimation of bat diversity in species richness and abundance, the use of autonomous recorders is not exempt from bias. We acknowledge that this sampling approach could have led to an underestimation of species richness. For instance, given that areas with closed arboreal vegetation are preferentially avoided when these bat recorders have been used (Wildlife Acoustics 2016), any species that do use these areas would not be recorded as occurring in the city. In addition, bat species from the Phyllostomidae family can produce low intensity calls (Kalko 2002), which could complicate recording these individuals with bat detectors, and we acknowledge that the abundance estimations for members of this family in our study may have been underestimated as a result. This could potentially lead to sampling bias in relative abundances and species richness due to systematic error across the BGUs, and the numbers of records for this family would not necessarily indicate whether these species are absent or 
in low numbers in our sampled BGUs. Nevertheless, these recorders do present lower bias than traditional sampling methods such as mist nets. In addition, security considerations prevented us from sampling in arboreal areas in the city.

The high suitability level BGUs recorded both the highest richness values and number of abundant species. Within cities, it is common for areas with arboreal vegetation to support an increased bat diversity compared to the open areas (Avila-Flores and Fenton 2005; Hourigan et al. 2010; Suarez-Rubio et al. 2018), since the areas with arboreal vegetation provide relatively more food resources (Threlfall et al. 2012b). Those highly suitable BGUs are characterized by presenting a cover of arboreal vegetation greater than $50 \%$, in comparison to the open and constructed areas. This suggests that arboreal vegetation in urban areas could play a key role for bat species in cities, as it may provide not only roosting sites (Entwistle et al. 1997) but also food resources (Gehrt and Chelsvig 2003) for the forest-dwelling bat species. Alternatively, these areas could be important for bat species adapted to foraging in areas with closed vegetation (Klingbeil and Willig 2009).

Morelia recorded the dominance of three bat species across all three suitability levels. Such a high dominance of few species is a pattern that is consistently found in modified habitats and has been observed in cities not only in bats but also other animal groups, such as birds (Ortega-Álvarez and MacGregor-Fors 2009; Dixon 2012; Moretto and Francis 2017). This is more evident at the low suitability level, since this presented the highest number of dominant species when compared to the other suitability levels. The increase in the number of dominant species is normally the result of changes in the habitat, creating more favorable local conditions for these bat species and then fostering their increase (Threlfall et al. 2012b). Low suitability BGUs, characterized by presenting the largest percentage of their area with no vegetation, could therefore favor the foraging strategy of the aerial insectivorous species that were recorded in these BGUs. Aerial insectivorous bat species foraging in open areas could then more efficiently exploit locally modified conditions. One example of this is the dominance of the aerial insectivorous species $P$. centralis, E. underwoodi and $M$. rufus. These three bat species belong to the Molossidae family, which is considered less susceptible to more open urban environments since most of the species in this family present higher body mass as well as a larger wing load and wing aspect (Jung and Kalko 2011). These features permit them to perform sustained flights at greater heights and higher speeds, enabling them to move over larger distances in one night (Norberg and Rayner 1987; Jung and Kalko 2011; Threlfall et al. 2012a). These features could allow them to better exploit urban areas compared to the other bat species in Morelia (Dixon 2012; Li and Wilkins 2014; Jung and Threlfall 2016, 2018). This guild could therefore be the most resilient to changes in conditions of suitability for bats in the city and be more widely distributed throughout the city.

Conversely, we found an increase in the richness and abundance of frugivorous bat species with an increased suitability level. This suggests that the low percentage of arboreal vegetation favoring aerial insectivorous bat species could also act as a limiting factor for other bat species in the city, such as the frugivorous bat species. Frugivorous bat species have been captured in Morelia city using mist nets (Martínez-Mijares 2016). Although there is no previous sampling in the high suitability level BGUs that 
could confirm the prior presence of frugivorous bats in this suitability level, sampling in these previous studies using mist nets did show frugivorous bats occurring in the city. Considering the suitability level that we assigned to each BGU in the city, sampling sites for these studies where frugivorous bats were recorded could be assigned to medium suitability level BGUs, given their location. One of the main drivers increasing the abundance of frugivorous bat species in urban parks is the amount and quality of fruits they use, as occurs with A. jamaicensis (Jara-Servín et al. 2017). The increase in richness and abundances of frugivorous and gleaning bat species in areas of medium and high suitability levels highlights the importance of the presence of areas of arboreal vegetation to the interior of cities. Of particular importance in fostering the presence of frugivorous bat species is the medium suitability level, despite its similarity to the low suitability level in terms of proportion of vegetation, given the large proportion of this suitability level BGUs in Morelia city.

During the rainy season, we recorded an increase in the number of individuals of insectivorous species such as $P$. hesperus, M. molossus, E. brasiliensis and M. megalophylla. The most common explanation for these seasonal changes is increased food availability due to the rainfall during this season, particularly in terms of the availability of prey for the insectivorous bat species. There are no studies in the city of Morelia evaluating seasonal fluctuations in the availability of flying insects on which bats could forage; however, the abundance of flying insects in areas near to Morelia characterized by oak forest, indicate that they increase in numbers during the months of highest rainfall (Jurado-Vargas 1990; Báez-SantaCruz 2011). An alternative explanation for the increase in abundance during the rainy season could be related to the synchronization of the timing of the independence of pups from their mothers with that of the highest availability of food resources during this season. This synchrony has been recorded in both Pipistrellus nathusii and Nictalus noctule, where an increase in abundance co-occurs with pup independence not only in forested areas in the Americas, but also in farmlands in Europe (Racey and Entwistle 2000; Klingbeil and Willig 2010; Heim et al. 2016). We do not have information on the timing of breeding bats in our study site; however, pregnant females of Myotis velifer have been reported at the end of the dry season in temperate forests close to Morelia (Ferreyra-García et al. 2018). Nursing and pregnant females of frugivorous Dermanura azteca and Artibeus lituratus have also been captured in Morelia city in the mid-dry season (Chavez-Estrada Pers. comm.). Therefore, the pups could potentially reach independence during the rainy season, when the abundance of food resources would be greater.

\section{City management implications}

The assignment of BGUs to a suitability level for bats showed geographic stratification according to suitability level. The BGUs to the north of the city were mostly of low suitability for bats, whereas those to the south of the city were mostly medium with a few of high suitability level. This is reflected in the distribution of urban parks in the city, since Morelia has nine urban parks, of sizes ranging from 10 to 118 ha, with an important presence of arboreal vegetation. Seven of these nine parks are in the southern part of the city, whereas only two are in the northern part. This indicates not only the lower presence of vegetation in the north of the city, but also that the north hosts fewer urban parks, where there is a dominance of low 
suitability level BGUs, and suggests that land use cover could be a key factor driving the suitability of areas in the urban matrix for bats and creating a north-south stratification of areas within the city.

The most marked difference between the low/medium and the high suitability levels is the percentage of arboreal vegetation areas in each BGU. Low and medium suitability areas were more similar in terms of the percentage of open and constructed areas, and thus over $90 \%$ of the city presents these features. This suggests that the sampled low and medium suitability level areas should be more similar in terms of both richness and abundance, and it could be expected that these segregate from the high suitability areas in the ordination space. Despite this, it was the areas of medium and high suitability levels that were more similar in diversity and were segregated from the low suitability areas, as indicated by NMDS plots. This could suggest that areas of medium and high suitability levels could be functionally similar as a result of the high proportion of medium and high suitability level areas close one to each other. Alternatively, the suitability level may influence not only species richness and abundance but also species composition, since there are species, such as the frugivores, that are restricted to medium and high suitability levels. Thus, while the medium and high suitability levels located in the south of the city could be similar in terms of diversity dimensions, they would not be functionally interchangeable due to differences in species composition.

The low suitability level represents one extreme of the suitability gradient, with gleaning and aerial insectivorous bat species occurring at this level of suitability. On the other side of the spectrum is the high suitability level, where we recorded an increase in relative abundance of frugivorous and gleaning insectivorous bat species. This suggests that some bat species will apparently be favored by the conditions for foraging provided by the presence of forested areas. Some other species, such as frugivorous bat species in areas of high suitability level, would require particular conditions to occur in this highly modified area. This acts to create a gradient in patterns of richness and abundance, but more markedly generates a potential spatial segregation to the interior of the city in bat species composition as the result of their different requirements and variability in the level of susceptibility to habitat modification based on the intrinsic characteristics of bat species.

Our study therefore indicates that suitability levels consistently influence the structuring of the bat assemblage in the city of Morelia. We found that species richness and feeding guilds, as well as the number of abundant species, increased in line with suitability, while the number of dominant species showed an inverse pattern. Morelia is considered a medium-sized city that presents accelerated growth (López et al. 2001). If this trend continues, the negative impact of this growth could be more marked in the long run. This is particularly true for those species using high suitability areas where there is a higher occurrence of individuals from the frugivorous feeding guild. This would mean that Morelia could keep losing feeding guilds not only from the high suitability areas, but also from the medium suitability areas to the south. This would also mean an increase in the abundance of some bat species that have been favored by the current modification status, as is the case of aerial insectivorous bat species. Several bat species require the presence of both open areas and those with arboreal vegetation, so it is important to not only maintain the existing arboreal vegetation areas in urban pacification plans for the city, but also to 
promote the creation of more urban parks and arboreal forested areas, particularly in the northern part of the city.

\section{Declarations}

\section{Acknowledgments}

The Mexican Consejo Nacional de Ciencia y Tecnología (CONACYT) provided a Masters degree scholarship (No. 704076) to MR-R, and a postdoctoral scholarship (No. 000240) to MAS-M. The Programa para el Desarrollo Profesional Docente (PRODEP) and Coordinación de la Investigación CientíficaUniversidad Michoacana de San Nicolás de Hidalgo provided support to AS-M. We also thank the Laboratorio Nacional de Análisis y Síntesis Ecológica (LANASE)-UNAM for providing facilities for conducting analyses related to the projects LN 293701 and 299033 supported by CONACyT. VS-M thanks The Tecnológico Nacional de México for providing financial support (Project No. 7194.19-P). We are thankful to Julian Equihua and Everardo Robredo from The Mexican Comisión Nacional para el Conocimiento y Uso de la Biodiversidad (CONABIO) for their kind help in the process to have access to bat recordings.

Funding: Consejo Nacional de Ciencia y Tecnología (CONACYT) provided scholarship No. 704076 to MRM, No. 000240 to MAS-M and support to the projects 293701 and 299033 via LANASE. The Programa para el Desarrollo Profesional Docente (PRODEP) and Coordinación de la Investigación Científica (CIC) provided support to AS-M. The Tecnológico Nacional de México provided support to VS-M (Project No. 7194.19-P)

Conflict of interest/Competing interest: The authors declare no conflict of interest.

Ethics approval: Not applicable

Consent to participate: All participants consent to their participation in this publication.

Consent for publication: All participants have read the manuscript and consent to the publication of this research

Availability of data and material: Not applicable

Code availability: Not applicable

Authors' contributions: MRR performed fieldwork, analyzed data and wrote the manuscript. VSM and MASM performed spatial analyses and wrote the manuscript. MRR, MASM, and ASM conceptualized the problem, designed the study, and wrote the manuscript. MRR, MASM, YHD and ASM improved the manuscript.

\section{References}


1. Agosta SJ (2002) Habitat use, diet and roost selection by the big brown bat (Eptesicus fuscus) in North America: A case for conserving an abundant species. Mamm Rev 32:179-198. https://doi.org/10.1016/j.na.2013.07.002

2. Arroyo-Rodríguez V, Rojas C, Saldaña-Vázquez RA, Stoner KE (2016) Landscape composition is more important than landscape configuration for phyllostomid bat assemblages in a fragmented biodiversity hotspot. Biol Conserv 198:84-92. https://doi.org/10.1016/j.biocon.2016.03.026

3. Avila-Flores R, Fenton MB (2005) Use of Spatial Features By Foraging Insectivorous Bats in a Large Urban Landscape. J Mammal 86:1193-1204. https://doi.org/10.1644/04-MAMM-A-085R1.1

4. Báez-SantaCruz J (2011) Hemiptera: Heteroptera de "Las Flores", municipio de Morelia, Michoacán, México. Bachelor Degree Thesis. Universidad Michoacana De San Nicolás De Hidalgo

5. Bates D, Maechler M, Bolker B, Walker S (2015) Fitting Linear Mixed-Effects Models Using Ime4. J Stat Softw 67:1-48. https://doi.org/10.18637/jss.v067.i01

6. Bazelman TC (2016) Effects of Urbanization on Bat Habitat Use in the Phoenix Metropolitan Region, Arizona, USA: A Multi-scale Landscape Analysis. Master Degree Thesis. Arizona State University

7. Blackthorn R (2013) A survey of microbat habitat use within the urban landscape of Lismore, New South Wales. Bachelor Degree Thesis. Southern Cross University

8. Breiman LEO (2001) Random Forests. Mach Learn 45:5-32

9. Brook ME, Kristensen K, Van Benthem KJ, et al (2017) glmmTMB Balances Speed and Flexibility Among Packages for Zero-inflated Generalized Linear Mixed Modeling. R J 9:378-400

10. Ceballos G, Arroyo-Cabrales J (2012) Lista actualizada de los mamíferos de México 2012. Rev Mex Mastozool 2:27-80. https://doi.org/10.1002/1521-3773(20010316)40:6<9823::AIDANIE9823>3.3.CO;2-C

11. Celis-Murillo A, Deppe J, Riddle J, Simons T (2014) An experimental evaluation of the performance of acoustic recording systems for estimating avian species richness and abundance. J Acoust Soc Am 136:2276-2276

12. Celis-Murillo A, Deppe JL, Allen MF (2009) Using soundscape recordings to estimate bird species abundance, richness, and composition. J F Ornithol 80:64-78. https://doi.org/10.1111/j.15579263.2009.00206.x

13. Chambers CL, Cushman SA, Medina-Fitoria A, et al (2016) Influences of scale on bat habitat relationships in a forested landscape in Nicaragua. Landsc Ecol 31:1299-1318. https://doi.org/10.1007/s10980-016-0343-4

14. Cisneros LM, Fagan ME, Willig MR (2015) Season-specific and guild-specific effects of anthropogenic landscape modification on metacommunity structure of tropical bats. J Anim Ecol 84:373-385. https://doi.org/10.1111/1365-2656.12299

15. Collado-Ardón R, Aguilar R, Álvarez-Gayou JL, et al (2001) El cambio de horario y la salud. Rev Fac Med UNAM 44:216-220. https://doi.org/10.1590/S1020-49891998000800005

16. CONABIO (2018) naturalista 
17. Dixon MD (2012) Relationship between land cover and insectivorous bat activity in an urban landscape. Urban Ecosyst 15:683-695. https://doi.org/10.1007/s11252-011-0219-y

18. Duchamp JE, Swihart RK (2008) Shifts in bat community structure related to evolved traits and features of human-altered landscapes. Landsc Ecol 23:849-860. https://doi.org/10.1007/s10980008-9241-8

19. Entwistle AC, Racey PA, Speakman JR (1997) Roost Selection by the Brown Long-Eared Bat Plecotus auritus. J Appl Ecol 34:399. https://doi.org/10.2307/2404885

20. Fabianek F, Gagnon D, Delorme M (2011) Bat Distribution and Activity in Montréal Island Green Spaces: Responses to Multi-Scale Habitat Effects in a Densely Urbanized Area. Ecoscience 18:9-17. https://doi.org/10.2980/18-1-3373

21. Faraway JJ (2016) Extending the Linear Model with R, Second. Chapman and Hall/CRC

22. Ferreyra-García D, Saldaña-Vázquez RA, Mendoza E (2017) Macrotus waterhousii en Morelia, México. Boletín la Red Latinoam y del Caribe los Murciélagos 8:20-22

23. Ferreyra-García D, Saldaña RA, Schondube JE (2018) La estacionalidad climática no afecta la fenología de murciélagos cavernícolas con dieta omnívora. Rev Mex Biodivers 89:488-496

24. Gehrt SD, Chelsvig JE (2003) Bat Activity in an Urban Landscape: Patterns at the Landscape and Microhabitat Scale. Ecol Appl 13:939-950

25. Gili F, Newson SE, Gillings S, et al (2020) Bats in urbanising landscapes: habitat selection and recommendations for a sustainable future. Biol Conserv 241:108343. https://doi.org/10.1016/j.biocon.2019.108343

26. Gomes LAC, Pires ADS, Martins MA, et al (2013) Species composition and seasonal variation in abundance of Phyllostomidae bats (Chiroptera) in an Atlantic Forest remnant, southeastern Brazil. Mammalia 79:61-68. https://doi.org/10.1515/mammalia-2013-0108

27. Gonsalves L, Law B (2018) Seasonal activity patterns of bats in North Sydney, New South Wales: Implications for urban bat monitoring programs. Aust Mammal 40:220-229. https://doi.org/10.1071/AM17031

28. Granados-Herrera J (2001) Caracterización de los llamados de ecolocalización de los murciélagos insectívoros de Yucatán, México. Bachelor Degree Thesis. Universidad Nacional Autonoma de México

29. Heim O, Schröder A, Eccard J, et al (2016) Seasonal activity patterns of European bats above intensively used farmland. Agric Ecosyst Environ 233:130-139. https://doi.org/10.1016/j.agee.2016.09.002

30. Hijmans RJ (2019) raster: Geographic Data Analysis and Modeling

31. Hill MO (1973) Diversity and Evenness: A Unifying Notation and Its Consequences. Ecology 54:427432. https://doi.org/10.2307/1934352

32. Hourigan CL, Catterall CP, Jones D, Rhodes M (2010) The diversity of insectivorous bat assemblages among habitats within a subtropical urban landscape. Austral Ecol 35:849-857. https://doi.org/10.1111/j.1442-9993.2009.02086.x 
33. Hourigan CL, Johnson C, Robson SKA (2006) The structure of a micro-bat community in relation to gradients of environmental variation in a tropical urban area. Urban Ecosyst 9:67-82. https://doi.org/10.1007/s11252-006-7902-4

34. Hsieh TC, Ma KH, Chao A (2016) iNEXT: an R package for rarefaction and extrapolation of species diversity (Hill numbers). Methods Ecol Evol 7:1451-1456. https://doi.org/10.1111/2041-210X.12613

35. IMPLAN (2018) Plan Municipal de Desarrollo 2018-2021 Morelia, Michoacán, México

36. INEGI (2021) XIV Censo General de Población y Vivienda 2020. In: Inst. Nac. Estadística y Geogr.

37. INEGI (1980) X Censo General de Población y Vivienda, 1980. In: Inst. Nac. Estadística y Geogr.

38. INEGI (2010) Manual de cartografía geoestadística. In: Inst. Nac. Estadística y Geogr.

39. Jara-Servín AM, Saldaña-Vázquez RA, Schondube JE (2017) Nutrient availability predicts frugivorous bat abundance in an urban environment. Mammalia 81:367-374.

https://doi.org/10.1515/mammalia-2015-0039

40. Jost L (2006) Entropy and diversity. Oikos 113:363-375. https://doi.org/10.1111/j.2006.00301299.14714.x

41. Jung K, Kalko EKV (2011) Adaptability and vulnerability of high flying Neotropical aerial insectivorous bats to urbanization. Divers Distrib 17:262-274. https://doi.org/10.1111/j.1472-4642.2010.00738.x

42. Jung K, Kalko EK V. (2010) Where forest meets urbanization: foraging plasticity of aerial insectivorous bats in an anthropogenically altered environment. J Mammal 91:144-153. https://doi.org/10.1644/08-MAMM-A-313R.1.

43. Jung K, Threlfall C (2016) Urbanisation and Its Effects on Bats A Global Meta-Analysis. In: Bats in the Anthropocene: Conservation of Bats in a Changing World. pp 13-33

44. Jung K, Threlfall CG (2018) Trait-dependent tolerance of bats to urbanization: a global metaanalysis. Proc R Soc B Biol Sci 285:1-9

45. Jurado-Vargas CMA (1990) Inventario de Lepidópteros diurnos del vivero forestal "Lázaro Cárdenas" municipio de Morelia, Michoacán, México. Bachelor Degree Thesis. Universidad Michoacana De San Nicoás De Hidalgo

46. Kalko EKV (2002) Neotropical leaf-nosed bat (Phyllostomidae): “Whispering” bats as candidates for acoustic surveys? In: Bat echolocation research: tools, techniques and analysis. Bat Conservation International, Austin, EE.UU., pp 63-69

47. Kalko EK V., Handley CO, Handley D (1996) Organization, diversity and long term dynamics of a Neotropical bat community. In: Long term studies in vertebrate communities. Academic Press, Los Angeles, pp 503-533

48. Klingbeil BT, Willig MR (2009) Guild-specific responses of bats to landscape composition and configuration in fragmented Amazonian rainforest. J Appl Ecol 46:203-213. https://doi.org/10.1111/j.1365-2664.2008.01594.x

49. Klingbeil BT, Willig MR (2010) Seasonal differences in population-, ensemble- and community-level responses of bats to landscape structure in Amazonia. Oikos 119:1654-1664. https://doi.org/10.1111/j.1600-0706.2010.18328.x 
50. Kloepper LN, Linnenschmidt M, Blowers Z, et al (2016) Estimating colony sizes of emerging bats using acoustic recordings. $\mathrm{R}$ Soc Open Sci 3:1-5. https://doi.org/10.1098/rsos.160022

51. Kuhn M (2008) Building predictive models in R using the caret package. J Stat Softw 28:1-26. https://doi.org/10.18637/jss.v028.i05

52. Kurta A, Teramino JA (1992) Bat community structure in an urban park. Ecography (Cop) 15:257-261. https://doi.org/10.1111/j.1600-0587.1992.tb00032.x

53. Li H, Wilkins KT (2014) Patch or mosaic: bat activity responds to fine-scale urban heterogeneity in a medium-sized city in the United States. Urban Ecosyst 17:1013-1031. https://doi.org/10.1007/s11252-014-0369-9

54. Lintott PR, Bunnefeld N, Fuentes-Montemayor E, et al (2014) City life makes females fussy: sex differences in habitat use of temperate bats in urban areas. $R$ Soc Open Sci 1:1-7

55. López-Baucells A, Torrent L, Rocha R, et al (2019) Stronger together: Combining automated classifiers with manual post-validation optimizes the workload vs reliability trade-off of species identification in bat acoustic surveys. Ecol Inform 49:45-53. https://doi.org/10.1016/j.ecoinf.2018.11.004

56. López E, Bocco G, Mendoza M, Duhau E (2001) Predicting land-cover and land-use change in the urban fringe A case in Morelia city, Mexico. Landsc Urban Plan 55:271-285

57. Martínez-Mijares J (2016) Evaluación del impacto de la ciudad de Morelia, sobre la estructura y composición de la comunidad de murciélagos. Bachelor Degree Thesis. Universidad Michoacana De San Nicolás De Hidalgo

58. McCleery R (2010) Urban Mammals. In: Urban Ecosystems Ecology. American Society of Agronomy, Crop Science Society of America, Soil Sience Society of America, pp 87-102

59. Medellín R, Arita H, Sánchez O (2007) Identificación de los murciélagos de México, Clave de campo, 2nd edn. Consejo Nacional de Ciencia y Tecnología, Instituto de Ecología, UNAM, México

60. Meyer CFJ, Fründ J, Lizano WP, Kalko EKV (2008) Ecological correlates of vulnerability to fragmentation in Neotropical bats. J Appl Ecol 45:381-391. https://doi.org/10.1111/j.13652664.2007.01389.x

61. Miguélez D, Mazé RA, Ansola G, Valladares LF (2013) La comunidad de coleópteros y hemípteros acuáticos de un arroyo costero cantábrico (norte de España): composición, variación estacional e influencia de los factores ambientales. Limnetica 32:47-60. https://doi.org/10.23818/limn.32.06

62. Miller BW (2001) A method for determining relative activity of free flying bats using a new activity index for acoustic monitoring. Acta Chiropterologica 3:93-105. https://doi.org/10.1111/j.14724642.2010.00738.x

63. Montiel S, Estrada A, León P (2006) Bat assemblages in a naturally fragmented ecosystem in the Yucatan Peninsula , Mexico: species richness, diversity and spatio-temporal dynamics. J Trop Ecol 22:267-276. https://doi.org/10.1017/S026646740500307X

64. Mora EC, Macías S, Rojas D, et al (2002) Aplicación de métodos bioacústicos y convencionales en la caracterización de la comunidad de murciélagos de la cueva del Indio, Tapaste, La Habana, Cuba. Rev Biol 16:123-129 
65. Moreno CE (2001) Métodos para medir la biodiversidad. Manuales y Tesis SEA 1:84. https://doi.org/10.1371/journal.pone.0103709

66. Moreno CE, Barragán F, Pineda E, Pavón NP (2011) Reanálisis de la diversidad alfa: alternativas para interpretar y comparar información sobre comunidades ecológicas. Rev Mex Biodivers 82:1249-1261. https://doi.org/10.1017/CB09781107415324.004

67. Moreno CE, Calderón-Patrón JM, Arroyo-Rodríguez V, et al (2017) Measuring biodiversity in the Anthropocene: a simple guide to helpful methods. Biodivers Conserv 26:2993-2998. https://doi.org/10.1007/s10531-017-1401-1

68. Moretto L, Francis CM (2017) What factors limit bat abundance and diversity in temperate, North American urban environments? J Urban Ecol 3:1-9. https://doi.org/10.1093/jue/jux016

69. Norberg UM, Rayner JM V. (1987) Ecological Morphology and Flight in Bats (Mammalia; Chiroptera): Wing Adaptations, Flight Performance, Foraging Strategy and Echolocation. Philos Trans R Soc B Biol Sci 316:335-427. https://doi.org/10.1098/rstb.1987.0030

70. Novaes RLM, Souza RF, Felix S, et al (2017) Seasonality and habitat influence on bat assemblage structure in an urban Atlantic Forest remnant from Southeastern Brazil. Mammalia 81:265-274. https://doi.org/10.1515/mammalia-2015-0115

71. Núñez-Garduño A (2005) Los mamíferos silvestres de Michoacán. Coordinación de la Investigación Científica Facultd de Biología, Morelia, México

72. Oksane J, Blanchet GF, Friendly M, et al (2019) vegan: Community Ecology Package

73. Oprea M, Mendes P, Vieira TB (2009) Do wooded streets provide connectivity for bats in an urban landscape? Biodivers Conserv 18:2361-2371. https://doi.org/10.1007/s10531-009-9593-7

74. Ortega-Álvarez R, MacGregor-Fors I (2009) Living in the big city: Effects of urban land-use on bird community structure, diversity, and composition. Landsc Urban Plan 90:189-195. https://doi.org/10.1016/j.landurbplan.2008.11.003

75. Pio DVV, Clarke FM, MacKie I, Racey PA (2010) Echolocation calls of the bats of Trinidad, West Indies: Is guild membership reflected in echolocation signal design? Acta Chiropterologica 12:217-229. https://doi.org/10.3161/150811010X504716

76. R Core Team (2020) R: A Language and Environment for Statistical Computing

77. Racey PA, Entwistle AC (2000) Life-history and Reproductive Strategies of Bats. In: Reproductive biology of bats. Academic Press, pp 367-370

78. Ramírez-Mejía AF, Urbina-Cardona JN, Sánchez F (2020) Functional diversity of phyllostomid bats in an urban-rural landscape: A scale-dependent analysis. Biotropica 52:1168-1182. https://doi.org/10.1111/btp.12816

79. Ramos R, Meza V (2017) Efectos De Algunos Factores Meteorológicos Sobre La Concentración De Esporas De Hongos En La Plaza San Martín De Lima. Ecol Apl 16:143-149. https://doi.org/10.21704/rea.v16i2.1018

80. Rodríguez-Aguilar G, Orozco-Lugo CL, Vleut I, Vazquez LB (2017) Influence of urbanization on the occurrence and activity of aerial insectivorous bats. Urban Ecosyst 20:477-488. 
https://doi.org/10.1007/s11252-016-0608-3

81. Rollinson DP, Coleman JC, Downs CT (2013) Seasonal Differences in Foraging Dynamics, Habitat Use and Home Range Size of Wahlberg's Epauletted Fruit Bat in an Urban Environment. African Zool 48:340-350. https://doi.org/10.3377/004.048.0218

82. Salvarina I, Gravier D, Rothhaupt KO (2018) Seasonal bat activity related to insect emergence at three temperate lakes. Ecol Evol 8:3738-3750. https://doi.org/10.1002/ece3.3943

83. Servicio Meteorológico Nacional (2019) Datos climáticos de la estación 00016080"MORELIA (Centro)". In: Norm. Clim. por estado

84. Suarez-Rubio M, Ille C, Bruckner A (2018) Insectivorous bats respond to vegetation complexity in urban green spaces. Ecol Evol 8:3240-3253. https://doi.org/10.1002/ece3.3897

85. Threlfall C, Law B, Penman T, Banks PB (2011) Ecological processes in urban landscapes: mechanisms influencing the distribution and activity of insectivorous bats. Ecography (Cop) 34:814826. https://doi.org/10.1111/j.1600-0587.2010.06939.x

86. Threlfall CG, Law B, Banks PB (2012a) Sensitivity of insectivorous bats to urbanization: Implications for suburban conservation planning. Biol Conserv 146:41-52.

https://doi.org/10.1016/j.biocon.2011.11.026

87. Threlfall CG, Law B, Banks PB (2012b) Influence of landscape structure and human modifications on insect biomass and bat foraging activity in an urban landscape. PLoS One 7:1-10. https://doi.org/10.1371/journal.pone.0038800

88. Trejo-Ortiz A (2011) Caracterización acústica de los murciélagos insectívoros del Parque Nacional Huatulco, Oaxaca. Master Degree Thesis. Instituto Politécnico Nacional

89. Turner BL, Meyer WB, Skole DL (1994) Change: Global Integrated Study Towards an Integrated Study. Ambio 23:91-95

90. Wildlife Acoustics (2016) Song Meter SM4BAT FS. User Guide

91. Zamora-Gutierrez V, Lopez-gonzalez C, Gonzalez MCM, et al (2016) Acoustic identification of Mexican bats based on taxonomic and ecological constraints on call design. Methods Ecol Evol 7:1082-1091. https://doi.org/10.1111/2041-210X.12556

\section{Tables}

Table 1. Average percentage of cover type per suitability level. Range is indicated in parenthesis.

\begin{tabular}{llll} 
& Open area (\%) & Constructed area (\%) & Arboreal vegetation (\%) \\
\hline Low suitability & $56.0(48.0-64.0)$ & $42.0(32.0-52.0)$ & $2.0(0.0-5.0)$ \\
\hline Medium suitability & $47.0(39.0-58.0)$ & $39.0(25.0-54.0)$ & $14.0(7.0-24.0)$ \\
\hline High suitability & $33.0(18.0-42.0)$ & $15.0(10.0-19.0)$ & $52.0(42.0-63.0)$
\end{tabular}


Table 2. Results from the generalized linear mixed models (GLMMs) for q0, q1, q2, and relative bat abundance for suitability level and the dry and rainy seasons. High suitability level and rainy season are included in the intercept. 95\% confidence intervals are shown in parenthesis.

\begin{tabular}{|c|c|c|c|c|c|c|c|c|}
\hline \multirow[t]{2}{*}{ Predictors } & \multicolumn{2}{|l|}{ q0 } & \multicolumn{2}{|l|}{ q1 } & \multicolumn{2}{|l|}{ q2 } & \multicolumn{2}{|c|}{ Relative abundance } \\
\hline & Estimates & $p$ & Estimates & $p$ & Estimates & $p$ & Estimates & $p$ \\
\hline Intercept & $\begin{array}{l}5.49 \\
(4.28- \\
7.05)\end{array}$ & $<0.001$ & $\begin{array}{l}1.19 \\
(1.04- \\
1.35)\end{array}$ & $<0.001$ & $\begin{array}{l}0.57 \\
(0.22- \\
0.92)\end{array}$ & 0.001 & $\begin{array}{l}4.48 \\
(2.20- \\
9.12)\end{array}$ & $<0.001$ \\
\hline $\begin{array}{l}\text { Dry } \\
\text { season }\end{array}$ & $\begin{array}{l}0.83 \\
(0.71- \\
0.98)\end{array}$ & 0.03 & $\begin{array}{l}-0.3(-0.39 \\
--0.20)\end{array}$ & $<0.001$ & $\begin{array}{l}0.42 \\
(0.11- \\
0.72)\end{array}$ & 0.007 & $\begin{array}{l}1.08 \\
(0.80- \\
1.45)\end{array}$ & 0.617 \\
\hline $\begin{array}{l}\text { Low } \\
\text { suitability } \\
\text { level }\end{array}$ & $\begin{array}{l}0.70 \\
(0.50- \\
0.97)\end{array}$ & 0.033 & $\begin{array}{l}-0.3(-0.52 \\
--0.08)\end{array}$ & 0.008 & $\begin{array}{l}0.35 \\
(0.05- \\
0.66)\end{array}$ & 0.023 & $\begin{array}{l}0.73 \\
(0.27- \\
1.92)\end{array}$ & 0.519 \\
\hline $\begin{array}{l}\text { Medium } \\
\text { suitability } \\
\text { level }\end{array}$ & $\begin{array}{l}0.86 \\
(0.62- \\
1.19)\end{array}$ & 0.355 & $\begin{array}{l}-0.1(-0.32 \\
-0.11)\end{array}$ & 0.336 & $\begin{array}{l}0.22 \\
(-0.10- \\
0.54)\end{array}$ & 0.17 & $\begin{array}{l}0.58 \\
(0.22- \\
1.53)\end{array}$ & 0.272 \\
\hline $\begin{array}{l}\text { Marginal } \\
\mathrm{R}^{2}\end{array}$ & 0.118 & & 0.057 & & 0.013 & & 0.017 & \\
\hline
\end{tabular}

Confidence intervals are shown in parenthesis. Rainy season and High suitability level are in the intercept as references

\section{Supplementary Figure}

Supplementary Figure $4 c$ is not available with this version.

\section{Figures}




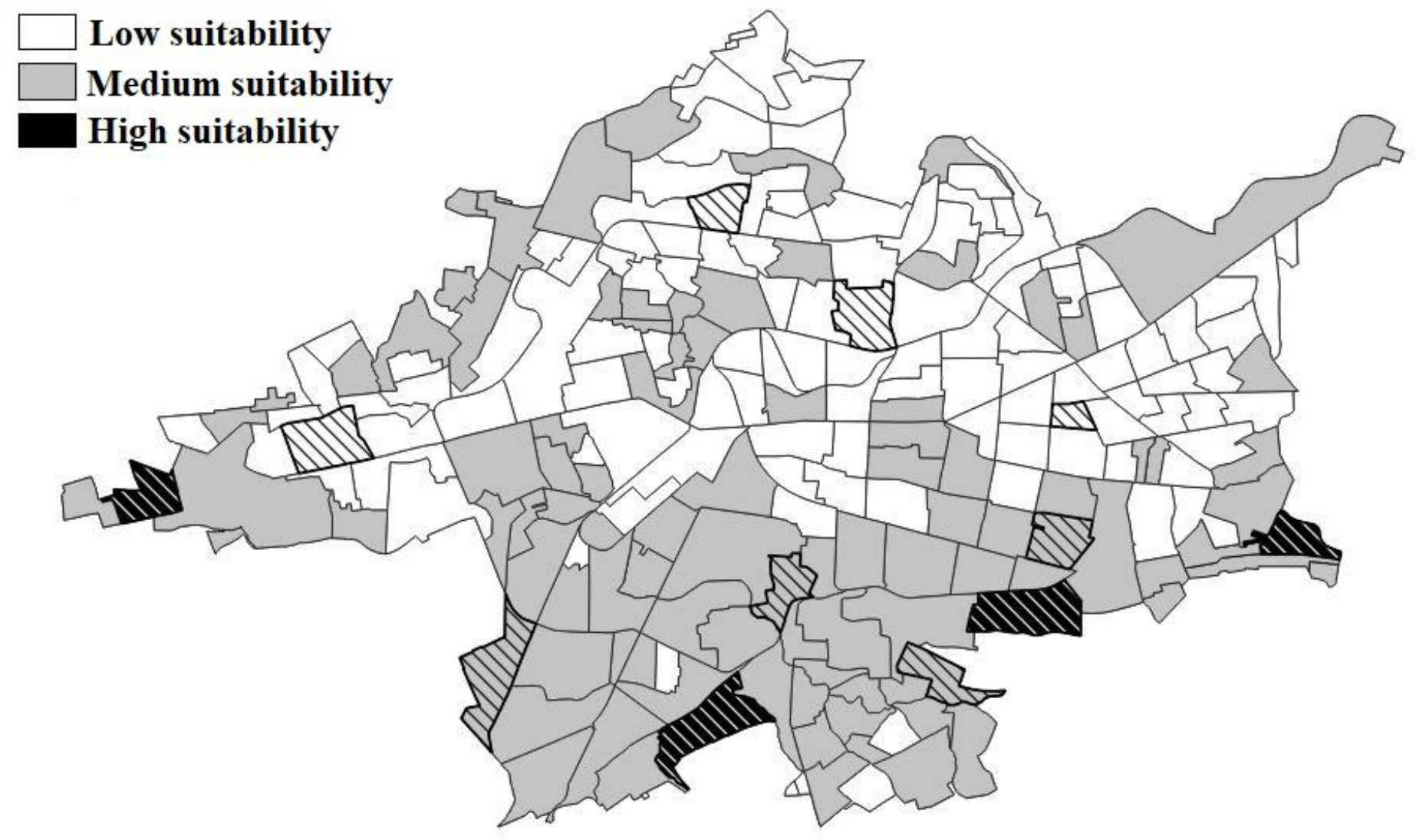

Figure 1

Map of the city of Morelia, presenting suitability levels for the presence of bats. The BGUs with diagonal hatching represent the sites sampled.
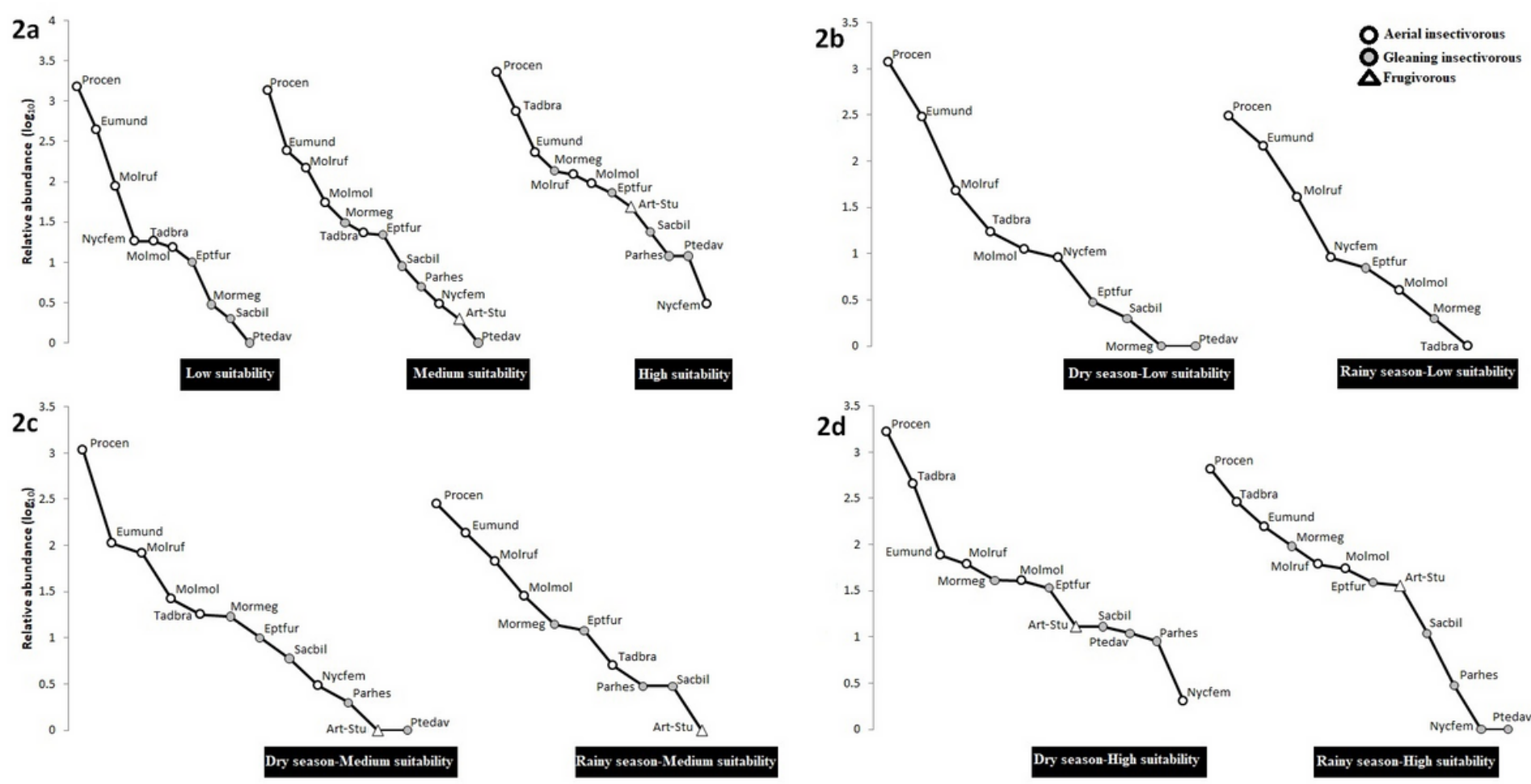

Dry season-High suitability

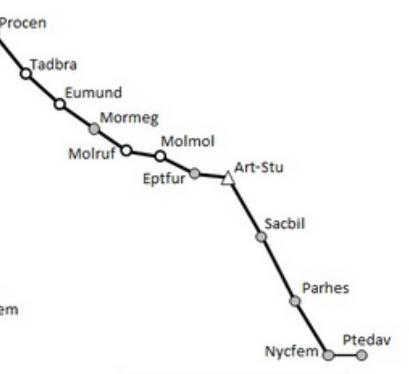

Rainy season-High suitability 
Figure 2

Rank abundance plots for bat species: a) Complete sampling period by suitability level: b) low bat suitability level per season, c) medium bat suitability level per season, d) high bat suitability level per season. Name of bat species according to Supplementary Material, Table 2.

Figure 3
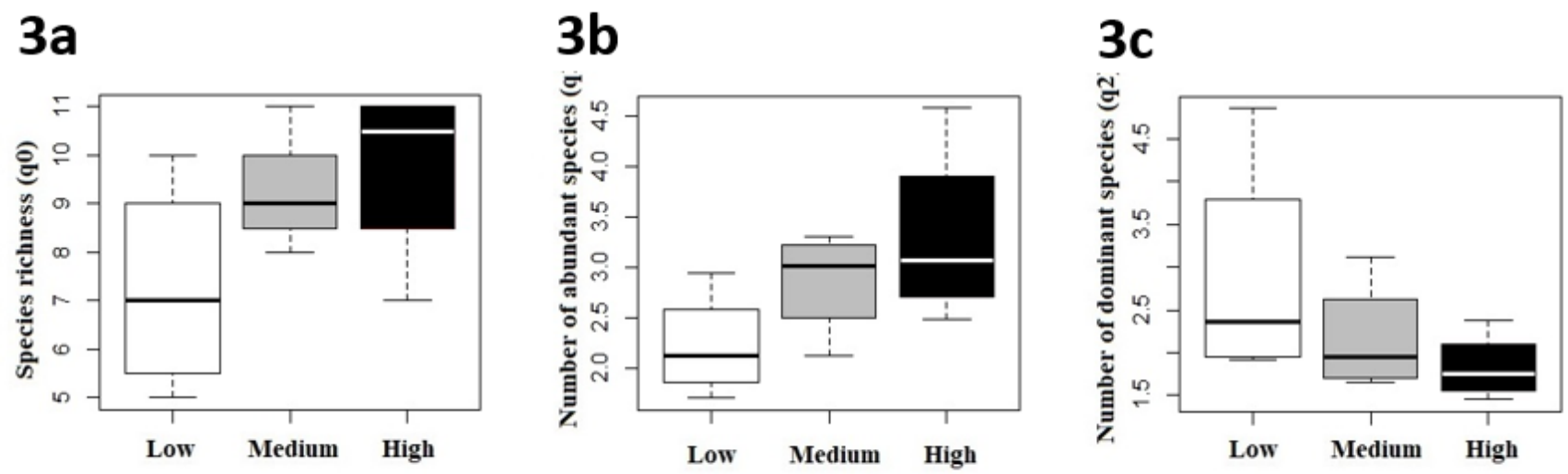

\section{3d}

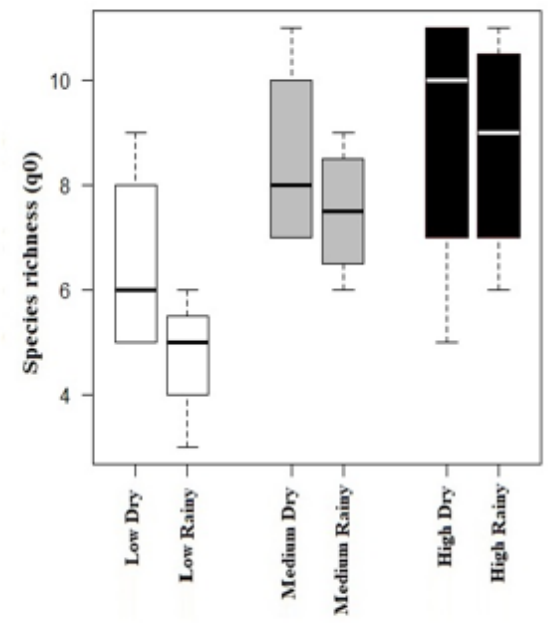

3e

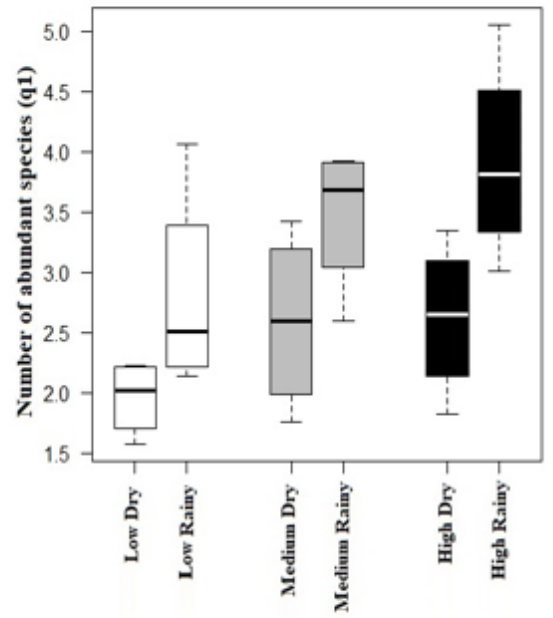

$3 f$

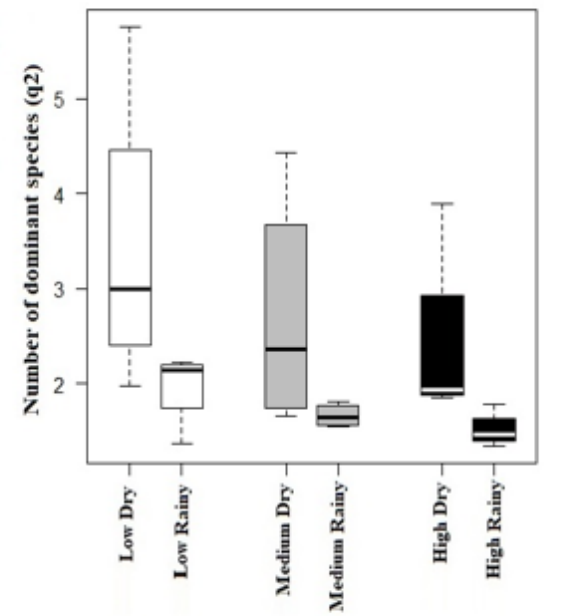

\section{Figure 3}

Box plot for the three first Hill numbers for bat diversity in the city of Morelia per suitability level. Lines over the bars indicate standard deviation. The top part of the plot indicates the annual sampling period, while the lower part shows the comparison between the dry and rainy seasons. a) and d) species richness (q0); b) and e) number of abundant species (q1);c) and f) number of dominant species (q2). 

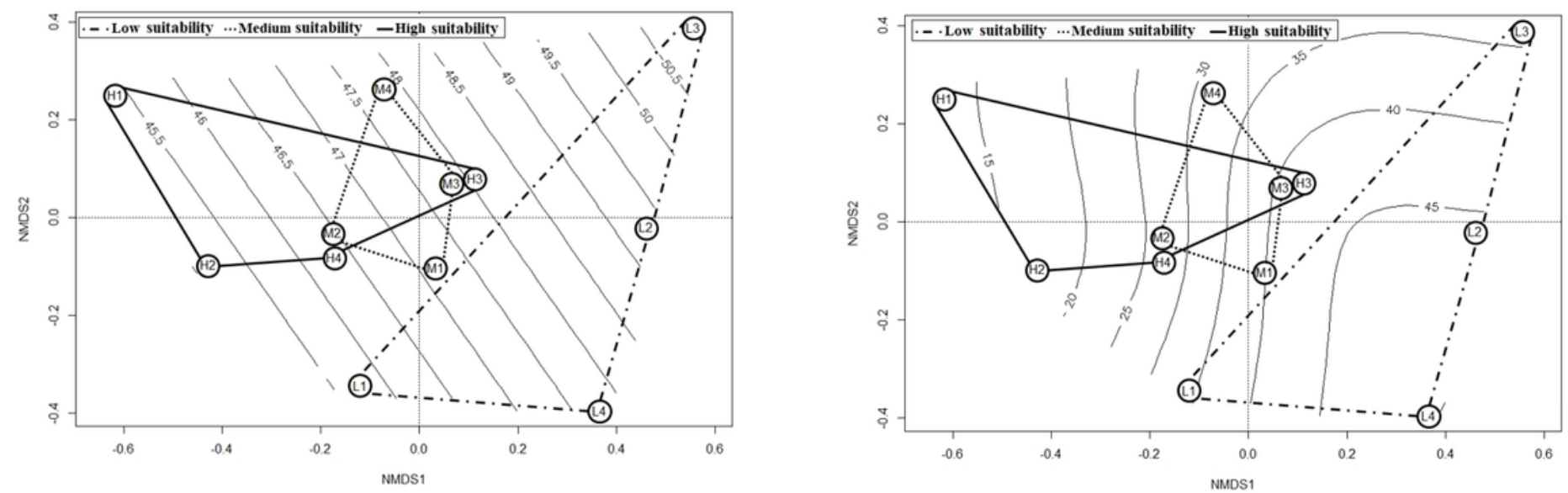

$4 \mathrm{c}$

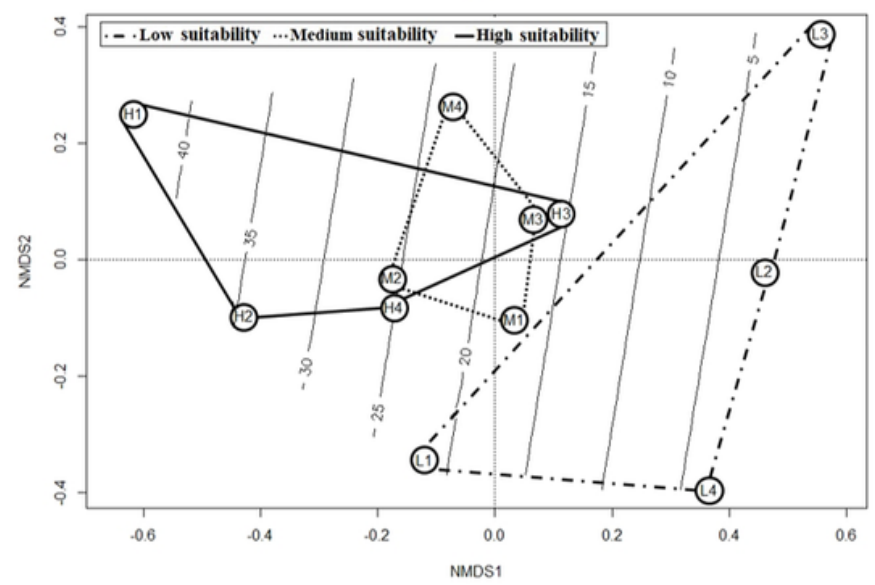

\section{Figure 4}

Biplot of the non-metric multidimensional scaling (NMDS) for the complete sampling period, showing the similarity among BGUs and overlay of percentage of: a) open areas, b) constructed areas and c) arboreal vegetation cover types and BGUs, for all three suitability levels. The suitability level for each BGU is indicated by a letter within a circle and its corresponding polygon

\section{Supplementary Files}

This is a list of supplementary files associated with this preprint. Click to download.

- SupplementarymaterialFigures13Jun2021.docx

- SupplementarymaterialTables13Jun2021.docx 